\title{
Problems and Transformation Plan of the Elderly Community in Beijing
}

\author{
Yi Wang \\ Beijing Jiaotong University, 100044, China \\ 19724027@bjtu.edu.cn
}

\begin{abstract}
In Beijing, the problem of population aging is severe, and the population aging problem has already become a social concerned important issue. However, what is more concerned is that many young people due to work, study, marriage and other reasons can not live with their parents, which lead to a lot older people living alone. Nowadays, it is often seen that sudden death tragedies happen to the elderly living alone, which also raises society's focus. How can we do to help the elderly living alone? Since many older people choose to provide for the aged at home, how can the elderly community do for the older people living alone? Aging is often regarded as a heavy topic, but there are a lot we can do to help the elderly live a better life.
\end{abstract}

Keywords: Elderly; Elderly Community; Beijing; Elderly Service Institution; Design Manager.

\section{Background Information}

In contemporary China, with the gradual improvement of living and medical standards, the problem of population aging has become society's focus. In Beijing, the capital city of China, the population aging problem becomes more and more serious. The results of China's seventh population census report shows that the total population of Beijing is about 22 million, of which about 4.3 million are aged 60 and over. In addition, the growth rate of Beijing's aging population is also worrying. According to Huang Shisong's report (2021), 'the population over 60 years old in Beijing will increase by more than 80000 in 2021 '. Beijing has already entered a moderately aging society.

In addition, the problem of population aging is also quite worrying, and the negative impact of this problem is further exacerbated. Among the 4.3 million older people in Beijing, about $60 \%$ are 'empty nesters' (Huang Shisong, 2021). According to Ma Xikui's (2019) analysis, the family pension has a long history in China, and home-based elderly care is a common way of providing for the aged in Beijing. In Beijing, there are about $90 \%$ of the elderly choose to provide for the aged at home, and $6 \%$ of the elderly prefer to provide for the aged in the community. These two ways are collectively referred to as home-based elderly care. However, due to the rapid development of Chinese society, it is common for young people to live separately from the elderly because of studies, work, marriage and other reasons. Therefore, the care of the elderly has become more challenging for the younger generation to achieve.

\section{Introduction to the Essay}

Facing the thorny problem of empty nesters, what can we do to help this particular group (empty nesters)? From the perspective of the design manager, this essay will discuss what can design managers do to coordinate the relationship between the elderly and the elderly community. Firstly, this essay will be based on the investigation of the elderly communities in Beijing, to analyze the existing shortcomings of the elderly service institution in the elderly communities. Secondly, this essay will put forward possible improvement suggestions for the elderly community in Beijing. At the same time, this essay will from the perspective of the design manager to analyze how can the community provide help for the empty nesters, and optimize the function of community service institutions while ensuring the regular operation of the community. In the end, this essay will discuss what further improvements can the community service institutions do for the elderly in now and future. 


\section{Finding and Defining Problems}

According to Cooper and Lockwood (2011), 'as a design manager, we should be good at finding problems in life, summarizing and defining problems according to the root causes of the problem, so as to help enterprises better carry out work and solve problems. In recent years, with the socioeconomic development and the improvement of medical level, people's life quality has been significantly improved, and people's life expectancy has also increased. However, the elderly population also increases year by year. As one of the most developed cities in China, the problem of population aging in Beijing has always been not optimistic. Moreover, with a variety of traditional family issues, more than half of the older people in Beijing have the situation of home-based elderly care. Therefore, what problems are the older people (especially empty nesters) facing in Beijing?

According to Hu Huiqin's (2018) report, many older people live in old communities in Beijing, and most of them live alone. In the old residential areas of Beijing, there are many common but unsolved problems such as the old buildings and facilities, crowded and narrow streets, and inconvenient transportation. In addition, for the elderly, their physical health and self-care ability will become worse as time goes by. What is more worrying is that the number of older people who live alone in Beijing are not optimistic, and most of them are accompanied by incurable chronic diseases. Moreover, most times, young people (especially the children of the elderly) are unable to accompany and take care of their parents due to work and other situations. In general, in Beijing, older people's life quality is unsatisfactory.

However, from the perspective of the overall social development in Beijing, although Beijing has a large elderly population, the advantage of the city mainly lies in its developed economy. Moreover, this city also has a large young labor force and a relatively 'perfect' urban infrastructure. Under the influence of variety factors, 'community nursing service' becomes a popular way for the elderly to choose. Lv Shan (2009) gave a definition to the 'community nursing service', 'the community nursing service is a way to make full use of the existing resources of the community, so that the elderly can receive relativity professional health care services at home'. In addition, the community nursing service can also satisfy the elderly in life care, medical care, mental care, and even in the rights and interests protection.

According to Zeng Shan's (2019) analysis, 'nowadays, the role of China's elderly service institutions is more inclined to nursing homes with "nanny care". However, community nursing service is different from this. In Beijing, most elderly communities are equipped with elderly service institutions. Nevertheless, these institutions also have many unsolved tough problems. For example, nowadays, most young people in Beijing are unwilling to invest in serving the elderly, which leads to a shortage of service personnel. More importantly, many communities elderly service institutions cannot attract the attention of the older people and their family members, and these service institutions also cannot win the trust of the elderly. All kinds of intractable problems lead to the fact that the way of 'community nursing service' cannot serve the elderly well. Therefore, what feasible schemes can design managers provide to the community elderly service institutions? Based on the current elderly service problems of the elderly living alone in Beijing, how can the elderly service institutions provide help for the older people?

\section{What can the Design Manager do for the Community?}

As design managers, we should ponder problems from a more comprehensive perspective (Jerrard \& Hands, 2007). That is to say, as design managers, we should take into account the needs of customers and the interests of the enterprise at the same time. Just as Topalian (1990) stated, 'design managers should neither ignore the needs of customers nor make the enterprise lose profits', which requires the design manager to have a strong coordination ability. As the design manager of coordinating the older people and the elderly community service institutions, it is not easy to coordinate the potential contradictions. According to the analysis of Lv Shan (2009), Chinese traditional elderly communities usually have the following problems: poor community managing, 
short of service personnel and finances, backward community infrastructure, as well as the imperfect community elderly service system. Topalian (1990) has stated in his book 'when an enterprise is facing many problems that are difficult to solve, the design manager can gradually try to solve the problems from easy to difficult', which requires the design manager to have a clear understanding of the problems. What's more, the design manager can also draw up feasible solutions, brainstorm with the other designers in the design team, and put forward innovative ideas (Bruce \& Bessant, 2002). Through brainstorming, the design manager can summarize the feasible solutions, and further launch a complete reform strategy for the elderly service institutions.

Based on the existing defects of the elderly service institutions in communities, design managers can substitute themselves into the identity of the elderly. Design managers can go to the elderly communities (especially the elderly service institutions in the elderly communities) around them and find out the problems that can be quickly adjusted and improved in a short time. Therefore, through quickly role reversal with the elderly and field research, design managers can quickly find out the potential problems, thus improving the time efficiency of the whole project. In addition, as a design manager, it is crucial to focus on the division of labor and the cooperation of the design team (Oakley, 1990). At the preliminary research stage, the designer manager should realize that only with the ability of one design team, it is impossible to investigate all the elderly communities in Beijing. Therefore, before the design team starts investigating, the design manager needs to collect the basic information about the elderly communities in Beijing, to better plan the investigation areas. For example, based on the current capacity of the design team, how many elderly communities in Beijing can the design team investigate? Are these investigated elderly communities' representative? Design managers should coordinate for these problems before improving the elderly service institutions in communities, which is a big challenge for the design manager.

According to the survey of Zhang Qiang (2019), 'Beijing is one of the most representative aging cities in China, and Chaoyang District has the largest aging population'. Therefore, what can design managers do base on the social situation in Beijing? Under limited time and conditions, design managers can find the elderly communities with typical problems in Chaoyang District to conduct further research. Thus, design managers can obtain more favorable information, and provide more opinions and adjustments for the elderly service institutions in the elderly communities. As Oakley (1990) stated, 'It is important for design managers to empathize with the research members'. For example, design managers can also understand older people's lives through a more comprehensive visit and research. In addition, the particularity of the elderly group is also reflected in the need for companionship and nursing care. According to Wang Bo's (2016) survey on the elderly communities in Chaoyang District, the service needs of the elderly in the community are in three levels: high, medium and low, followed by basic physiological needs, spiritual needs and social service needs. Therefore, if the design team wants to meet the "three levels' needs" of the elderly, the elderly service community needs to have relatively perfect service facilities and professional service personnel.

However, from another perspective, whether the elderly is willing to accept the community service institution's help is another tough problem that design managers are facing. Cao Junxue (2019) stated that the elderly in contemporary Chinese society is generally have the following problems: poor physical health, less-educated and ideological tradition. These problems have caused many older people to be unwilling to trouble others although their body is not optimistic. What is more worrying is that most of the empty nesters are usually not able to take good care of themselves. Moreover, because the elderly cannot realize their health problems in time, accidents often occur to them when they are living alone.

As a design manager, it is essential to coordinate the relationship between all aspects. In the elderly community, design managers should know how to coordinate the relationship between the elderly and the elderly service institution. As we discussed earlier, for the elderly service institution, the biggest problem of the elderly is that the elderly does not trust the elderly service institution, and they also do not want to trouble others. Based on this situation, design managers can build a feasible scheme for the elderly service institution, and implement the scheme within a certain time. By testing 
whether the scheme is effective, design managers can decide whether it is necessary to implement and promote the scheme in the future (Gorb, 1992). This method is called 'prototype testing' in the design management subject. Through quickly prototype tests, design managers can discover and solve more problems in a short time.

However, how can the design manager help the elderly community to carry out a feasible scheme? What can the community do? Based on the preferences of the elderly, the community can try to hold more cultural activities. For example, the elderly may prefer traditional cultural performances such as Peking Opera, and the community can try to hold activities related to Peking Opera. By holding the cultural activities, the design manager and the community manager can observe if the elderly like to attend the cultural activities. If the cultural activities win the older people's appreciation, the community can make more efforts in this aspect in the future. In addition, according to Gai Hongwei's survey, 'housekeeping, dining, medical services and emergency assistance are critical for the service needs of the elderly'. Therefore, the manager of the elderly community should put more focus on older people's daily life. Nowadays, it is often seen the sudden death tragedy happens to the elderly who are living alone. To avoid tragedy happening again, the elderly community should equip the older people with a professional medical service team. Moreover, this medical service team should be able to provide help for the elderly in anytime and anywhere. In addition, during the whole community transformation process, the design manager needs to coordinate the relationship between community elderly service institution and the elderly, which need the design manager to have good communication ability. In general, it is not easy for the design manager to plan a community suitable for the elderly.

As Topalian (1990) stated, 'once all the conditions are fulfilled, the design manager should consider from the perspective of economic, to decide whether the planning scheme is reasonable and feasible'. 'Capital' is often the key to the success of the project. If the community want to hire a professional medical and daily service team in the elderly service institution, that the community need to have sufficient financial support. As a design manager, on the one hand, the design manager needs to consider the fund operation status of the community. On the other hand, the design manager should often communicate with the elderly and the service team (as well as the workers in elderly service institution), so that the elderly can trust the elderly service institution and the service staff in the community. However, how can the service team win the trust of the elderly? If the service team wants the elderly to trust them, the team members need to accompany the elderly in their daily lives to make up for the regret that their (older people) children are not around. Moreover, when the elderly are sick and need help (especially when their children are not around), the service team should also be able to diagnose the condition of the elderly in time and provide medical services for the elderly when necessary. Donald A. Norman, an American cognitive psychologist, pointed out that spiritual companionship is a bridge to building a good relationship. Therefore, if the community elderly service institution (especially the service team) can serve the older people attentively, the elderly will also gradually accept the community's kindness.

How can the design manager coordinate the capital operation of the elderly community? It is not easy to cultivate a professional service team for the elderly community. Moreover, whether the time or economic cost to cultivate the service team is still a complex problem for the design manager. However, the design manager can help the elderly service institution win the support of the government and the elderly's families. Nowadays, with the development of the economy and the improvement of people's life quality, young people are more willing to make the elderly live a better life by hiring nannies. Therefore, the design manager can communicate with the older people's families to help the community raise funds. In addition, design managers can also try to apply for funds from the Beijing government, to win more financial support to improve elderly service institutions in the elderly communities. If the design manager can show the improved results of the elderly community to the Beijing government, it will be helpful to improve more elderly communities in Beijing in the future. If the pilot reform case of the elderly community can achieve a good result, 
the government will also assist the design team to do more elderly community reform in the future, and the problem of funds can be well solved.

\section{Conclusion}

This essay mainly discusses the problems that the elderly living alone in Beijing are facing, and this essay also puts from the perspective of the design manager to forward feasible transformation plans and suggestions for community elderly service institutions. Firstly, we introduced the background information about the older people in contemporary society, and analyzed the causes of the empty nesters in Beijing. In addition, based on Beijing's current social and economic situation, this essay discussed the current problems that the elderly communities and the elderly service institutions are facing. In the third part, this essay makes a more detailed analysis of the older people and the elderly communities in Beijing, and further analyzes their problems from the perspective of the design manager. Moreover, in the fourth part, this essay also gives feasible suggestions for the elderly communities in Beijing from the perspective of the design manager.

However, to discuss and analyze the problems are only one aspect, to make the elderly live a better life, there are still many areas for communities and elderly service institutions to improve. For example, it is a good choice to replace stairs with more slopes in the elderly community. By using gentle slopes can reduce the possibility of the elderly falling on stairs, and it is also more convenient to use the gentle slope for transportation. The community manager can also make more efforts to the elderly community's environment, for example, providing more wheelchairs for the disabled elderly, building more fitness equipment for the elderly to do physical exercise, and planting trees and flowers to make the community more beautiful. These are all good ways to make the elderly community more humanized. For the elderly living alone in Beijing, perhaps the family's company is what they most expect. Hopefully, we can no longer have the word 'empty nesters' in the future, and all the older people can live a better life.

\section{References}

[1] Bruce, M., \& Bessant, J. (2002). Design in Business: strategic innovation through design. Pearson Education, Essex.

[2] Cooper, R., Junginger, S. \& Lockwood, T. (2011). The Handbook of Design Management. Berg Publishing, London.

[3] Gorb, P. (1992) Design Management Education: a personal retrospective. Design Management Review, $3(3), 40-43$.

[4] Jerrard, R. \& Hands, D. (2007). Design Management: Exploring Fieldwork and Applications. Routledge Taylor Francis, London.

[5] Norman, D. (2004). Emotional design why we love (or hate) everyday things. New York: Basic Books.

[6] Oakley, M. (1990). Design Management: a handbook of issues and methods. Blackwell, London.

[7] Topalian, A. (1990). Design Leadership in Business: the role of non-executive directors and corporate design consultants. Journal of General Management, 16(2), 50-62.

[8] Cao, Junxue. \& Wei, Xiaoxue. (2021). A summary of urban community pension in contemporary China. Journal of Chongqing Three Gorges University, 37(196), 46-54.

[9] Gai, Hongwei. \& Liu, Bo. (2019). Discussion on improving the supply and operation mechanism of urban community elderly care service in China. Journal of Socialist Theory Guide, pp. 39-44.

[10] Hu, Huiqin. \& Wang, Xiaomeng. (2018). Discussion on the Improvement of Residential Environment in Old Residential Areas from the Perspective of Aging: Take Old Communities in Beijing as an Example. Architectural Practice, pp. 80-84.

[11] Huang, Shisong. (2021). Take a positive view of Beijing's aging population. China old people's daily, pp. $1-3$. 
[12] Lv, Shan. (2019). Thoughts on community pension in China. Journal of Shandong Agricultural Management Cadre College. pp. 56-59.

[13] Ma, Xikui. (2019). Design management of public medical space under the background of population aging. Journal of Shandong University of Arts. pp. 56-57.

[14] Qiu, Sichun., Wang, Jingmei., \& Huang, Changyi. (2018). The innovation way of community pension management system in contemporary China. Management World. pp. 172-173.

[15] Wang, Bo. (2016). Research on community pension in Beijing from the perspective of demand and supply -- Based on a survey of 12 communities in Chaoyang District. Social Science of Beijing. pp. 73-81.

[16] Zhang, Qiang. (2019). Exploration of elderly community medical and health service model in Beijing. Chinese Market. pp. 48-49.

[17] Zeng, Shan. (2019). Analysis on the current situation and Countermeasures of community elderly education in Beijing under the background of population aging. Journal of Beijing Xuanwu Hongqi Sparetime University. pp. 53-57. 